\title{
Adolescence Aggression as Related to Gender and Birth Order
}

\author{
Sabina Sultana and Laila Latif \\ Department of Psychology, University of Rajshahi, \\ Rajshahi-6205, Bangladesh
}

\begin{abstract}
In the present study an attempt was made to find out whether aggressive behaviour is related to gender and birth order of the adolescence. A Bengali version of the aggression scale of Edwards Personal Preference Schedule (EPPS) was administered to one hundred students from different colleges in Rajshahi city. In order to investigate the relationship between aggressive behaviour and gender, they were divided into two groups, male and female and comparisons were made between them, on the basis of the scores obtained on the aggression scale employing 't' test. Secondly, in order to study the relationship between aggressive behaviour and birth order, the respondents were divided into two groups- first born and last born and comparisons were made between the two groups. The results of the study suggest that males are more aggressive than females and the last born children are more aggressive than the first born children.
\end{abstract}

\section{Introduction}

Over the years many attempts have been made to study violence and aggressive behaviour. One of these studies shows that aggression is the result of being blocked or frustrated in an attempt to achieve a desired goal (Dollard, et al., 1939). Dollard and associates suggested that frustration leads to aggression and aggression leads to violence. This is known as frustration-aggression hypothesis.

A second theory which is based on animal studies suggests that aggression in humans is related to the fixed response patterns of aggression found in lower animals. According to this theory, aggressive behaviour is a natural response to specific situations rather than a learned response.

A third theory which is based on neurological studies suggests that aggression is the result of brain structures or, different levels of hormones or neurotransmitters. Researchers suggest that extreme aggression may be linked to disorders in neural mechanisms that regulate our emotions (e. g., Patrick, Bradley, and Lang, 1993). These neurological studies indicate that biological factors may indeed play a role in aggressive behaviour. 
Another explanation has been derived from learning theory. It argues that aggressive behaviour is acquired by observing aggressive models, by being reinforced for aggression, and by having pleasant stimuli associated with aggression.

Among these explanations, the first and last explanations seem to be more plausible. As for the other theories, while there may be fixed aggressive patterns of behaviour in lower animals, the evidence for such specific aggressive behaviour in human is weak. And although specific brain structures are involved in aggressive behaviour, and neurochemical and hormonal imbalances are occasionally related to aggression, the evidence that aggressive people are physiologically different from non-aggressive people is still tentative.

Currently, some of the researchers believe that human aggressive behaviour is primarily the result of learning, especially social learning (Eron, 1990). Again others believe that although aggression is not an inevitable response to frustrations, people often react to frustration by becoming aggressive. But such reactions to frustration appear to depend upon the individual and the specific situation.

People often seem to want a simple answer to the question of why some children and adolescence are more aggressive than others. Some want to blame the parents; others point to the impact of television violence or video games. In fact, the answer is much more complicated. Many researchers have found a number of different "risk factors" that increase the likelihood that a child or adolescence will engage in aggressive behaviour. These include:

1) Individual characteristics: A number of individual characteristics have been shown to increase a child's risk for aggressive behaviour. These include a difficult temperament as an infant, low intelligence, hyperactivity, impulsivity, and attention problems (Pepler and Slaby, 1994).

2) Home environment: Some characteristics of the home environment can increase the risk that a child will eventually become involved in aggressive behaviour. Children and teens who come from homes where parents are coercive or manipulative with their children, provide little emotional support, do not monitor their activities, or have little involvement in their lives are at greater risk for engaging in aggressive behaviour. Additionally, the use of harsh punishments or inconsistent discipline has been shown to be related to aggressive behaviour in children (Pepler, and Slaby, 1994). 
3) Relationships with peers: Coie, et al., (1990) found that because of their aggressive behaviour and lack of social skills, highly aggressive children are often rejected by their peers. This early rejection is predictive of later aggressive and violent behaviour. School failure, exposure to media violence, community and societal factors, poverty, joblessness, and societal acceptance of aggression all increase the risk of aggressive behaviour (Hann and Borek 2002; Coie and Dodge, 1997).

Studies have been conducted to investigate the relationship between birth order and different personality factors. Eisenman (1992) found that first born are more fearful than last born and middle born. He also reported from his result of this study that some first born show more anxiety and creativity. Kushnir (1978) reported that birth order differences in affiliation exit only in females and only in situations that produce higher anxiety in first born than in last born females. Schachter (1959) found that first born and only children become more anxious in anxiety-inducing situations than later born. Gates, Limberger, Crockett, and Hubbard (1988) reported from their study first borns as having less trait anxiety with girls exhibiting more anxiety than did boys overall. Shanbhag (1990) found that first born were more anxious than middle and last born.

Many research findings show that birth order is an important correlate of behaviour problems in adolescence. Less aggression and fewer frustrations of the first born are found in some studies while others (e.g., Benjamin et al., 1980) found that first born and only children show more aggressiveness and more anxious than later born. Toldos (2005) examined sex and age differences in aggression and found that, compared with girls, boys reported a more frequent use of physical and verbal aggression. However, for indirect aggression no differences were found between boys and girls. Begum, (1996) studied the sex difference in aggressive behaviour in children of Dhaka City. She found that according to mothers, $2.2 \%$ of boys and $1.5 \%$ of girls and according to teachers $2.6 \%$ of boys and $1.6 \%$ of girls have aggressive behaviour in the clinical range. She also noted that, on all items boys were judged to have significantly higher aggressive behaviour than girls. Begum, (1993) studied the behaviour problems of 627 (341 boys \& 286 girls) ten years old children in Dhaka city. The result showed that total behaviour problem scores varied significantly according to sex. Boys scored significantly higher than girls on most of the items. Islam and Huque (1996), on the other hand, found no significant sex differences in behaviour problem scores, though boys were found to be more involved in certain types of problem behaviours than girls. Thus, the studies reported so far provide us with some conflicting results. Some of the investigators have reported that boys are more aggressive than girls while some others found no gender differences in aggressive behaviour (Islam and Huque, 1996). 
As the above literature review indicates, a correlation between adolescence and aggression has been clearly demonstrated. Birth order plays an important role in the personality development of the people. Since birth order has an effect on personality development, it is expected that birth order may play an important role in the development of aggressive behaviour in the adolescence. But no study has been conducted so far to investigate the effect of birth order on aggressive behaviour in the context of Bangladesh. The present author feels the necessity of investigating the relationship between birth order and aggressive behaviour in the context of Bangladesh. Thus, the broad objective of the study was to investigate the relationship of aggressive behaviour of adolescence with gender and birth order. However, the specific objectives of the study were as follows:

i) to examine whether there is any significant difference between aggressive behaviour of males and females.

ii) to investigate whether there is any relationship between aggressive behaviour and birth order of males as well as of females.

\section{Method}

\section{Sample}

The participants of this study consisted of 100 (50 male and 50 female) college students (The original EPPS scale also developed on college students). Out of 50 male students, 25 were first born and 25 were the last born children of their parents. On the other hand, out of 50 female students, 25 were first born and 25 were last born children of their parents. They were purposively selected from different colleges of Rajshahi city in Bangladesh. Their ages ranged from 16 to 18 years. All of them came from middle class family.

\section{Measuring Instrument}

i) The Bengali version of aggression sub scale of Edwards Personal Preference Schedule (Eva, 2003) originally developed by Edwards and others in 1959 was used to measure aggressive behaviour. The Aggression scale of EPPS consists of 28 pairs of statements. The subject is to choose any one of the two statements, which is more characteristic of participants. The reliability and validity of Bengali version of the aggression scale were studied on Bangladeshi people. The test retest reliability was found 0.62 , which was highly significant.

ii) Personal information Blank: A personal information blank sheet was used to obtain the following information of the subjects: gender, age, parental occupation, and parental education. 


\section{Procedure}

A standardized procedure was employed as far as possible in the administration of the test. The test was administered on different days in different colleges. The testing room in the college was well ventilated and lighted and was free from noise and other interruptions. A few minutes conversation was carried out with each participant before administering the test to establish a rapport. The instruction for administration of the test as outlined in the manual was strictly followed. There was no time limit on completing the scale, but they were encouraged to work as rapidly as possible.

\section{Result}

In order to analyze the relationship between aggressive behaviour and gender, comparisons were made between male and female groups. Mean and SD were computed for each group separately and comparisons were made between the two groups employing “t” test (Table-1).

Table 1: The relationship between aggressive behaviour and gender.

\begin{tabular}{|l|l|l|l|l|l|l|}
\hline Sex & Mean & SD & SED & $\mathrm{t}$ & $\mathrm{df}$ & $\mathrm{P}$ \\
\hline Male & 11.5 & 2.396 & 0.504 & 6.94 & 98 & 0.001 \\
\hline & & & & & & \\
Female & 8.00 & 2.10 & & & & \\
\hline
\end{tabular}

Table- 1 shows that the average score was significantly $(\mathrm{P}<0.001)$ higher for male group than that for female group which indicates that the males are more aggressive than the females. 
In order to study the relationship between aggressive behaviour and birth order, the respondents were divided into two groups, first born and last born and comparisons were made between the two groups (first born and last born child) employing “ $t$ ” test (Table-2).

Table 2: The relationship between aggressive behaviour and birth order of children.

\begin{tabular}{|l|l|l|l|l|l|l|}
\hline Birth order & Mean & SD & SED & $\mathrm{t}$ & $\mathrm{df}$ & $\mathrm{P}$ \\
\hline First born & 8.5 & 2.098 & 0.566 & 3.85 & 98 & 0.001 \\
\cline { 1 - 4 } Last born & 11.00 & 2.90 & & & & \\
\hline
\end{tabular}

Table-2 shows that the average score of the last born respondents was significantly $(\mathrm{P}<0.001)$ higher than that of the first born respondents which suggests that the last born children are more aggressive than the first born children.

In order to study the effect of birth order in case of male, the male respondents were divided into two groups (first born and last born). Then comparisons were made between them employing " $t$ " test (Table-3).

Table 3: The aggressive behaviour of first born and last born male students

\begin{tabular}{|l|l|l|l|l|l|l|}
\hline Birth order & Mean & SD & SED & $\mathrm{t}$ & $\mathrm{df}$ & $\mathrm{P}$ \\
\hline First born & 10 & 1.45 & 0.59 & 5.08 & 98 & 0.001 \\
\cline { 1 - 4 } Last Born & 13 & 2.22 & & & & \\
\hline
\end{tabular}

From Table-3 it can be seen that last born male respondent's were significantly more aggressive than the first born male respondents. 
Table 4: The aggressive behaviour of first born and last born female students

\begin{tabular}{|l|l|l|l|l|l|l|}
\hline Birth order & Mean & SD & SED & $\mathrm{t}$ & $\mathrm{df}$ & $\mathrm{P}$ \\
\hline First born & 7.0 & 1.74 & 0.628 & 3.19 & 98 & 0.01 \\
\cline { 1 - 5 } Last born & 9.0 & 2.21 & & & & \\
\hline
\end{tabular}

The effects of birth order in case of female respondents were also analyzed. The results have been presented in Table-4. The table shows that the last born female respondents were significantly more aggressive than the first born female respondents. The result of this study indicates that the last born female respondents were also more aggressive than the first born female respondents.

\section{Discussion}

The aim of this study was to investigate the relationship of gender and birth order with aggressive behaviour of adolescence. The results presented in Table-1, show that males are more aggressive than females. This finding is consistent with the findings of other researchers (Begum, 1996; Burkley, et al., 1996; Coie, et al., 1982; Elliot, 1994; Maccoby and Jacklin, 1974; Loeber and Hay, 1997). Roberts and Bird (1972) found that at home, in school, and in the neighborhood boys break more rules and show more aggressive behaviour than girls. Boys are reported for more physical and verbal abuses but less indirect victimisation than girls. Girls are reported for greater use of compromise, obliging, and avoidance than boys but similar amounts of overt anger (Owens, et al., 2005). Tapper, et al., (2004) examined sex differences in levels of physical, verbal, and indirect aggression amongst primary school children. The results revealed significantly higher levels of observed physical aggression amongst boys as compared to girls. There are two possible reasons for this gender differences. Firstly, in our society boys are given more freedom than girls and are less often punished for misbehaviour on the grounds that "boys are to be rough", Secondly, boys often defy rules to show their masculinity and thus win peer approval. Begum (1993) found that in Bangladesh males are more aggressive than females. In our society girls are discouraged 
from early childhood to express any aggressive behaviour and society also shows negative attitude towards females showing such behaviour. Boys, on the other hand, are either encouraged, or at least allowed, to express aggression in many situations. For these reasons boys in Bangladesh may show more aggressive behaviour than girls.

The results (Table-2) also show that the average score of the last born respondents was significantly higher than that of the first born respondents which suggests that the last born children are more aggressive than the first born children. This finding is consistent with the findings of other researchers. Begum (1998) found that birth order itself has no definite role in increasing or decreasing problem behaviour in children. Some other factors such as family size, age spacing, physical health of the child, etc. may be related to birth order and play part in determining behaviour problems in the children. Hurlock (1968) found that middle-born children exhibit more aggressiveness than the first born and last born mainly due to feelings of inadequacy and inferiority resulting from parental negligence.

In order to study the effect of birth order in case of the males respondents were divided into two groups-first born and last born. Table-3 shows that last born male respondents had significantly higher aggressive responses than those of the first born male respondents. Similar effects of birth order were found in case of female respondents. The result (Table-4) shows that the last born female respondents were also more aggressive than the first born female respondents.

In explaining these findings of birth order effects on aggressive behaviour it can be said here that adolescents who perceive themselves as being neglected and non-favoured may experience feelings of inferiority, anger, depression and incompetence. In a recent study, 62\% of subjects reported that they believed one or both parents favoured one child in their family (Zervas and Sherman, 1994). Birth order was one of the main reasons subjects gave this reaction.

In our country, parents often seem to have higher expectations on their first borns and tend to perceive them as most intelligent, strong and often give them more control over their environment than last born children. They are also found to be more attentive to fulfill the needs of their first borns than the last borns. As a result, the last born children perceive themselves as the non- favoured children and become frustrated. Thus, the higher aggressive behaviour of the last born children can be explained in terms of frustration hypothesis.

To conclude, it may be said that males display more aggressive behaviour than females and that last born children are likely to show more aggressive behaviour than first born children. 


\section{References}

Barkley, R. A., K. R, Murphy, and D. Kwasnik. Motor vehicle driving competencies and risks in teens and young adults with attention deficit hyperactivity disorder. Pediatrics, 1996, 98, 1089-1095.

Begum, R. A study of behavioural problems in children in Dhaka city, Bangladesh. Unpublished Ph.D. Thesis, University of Vienna, Austria. 1993.

Begum, R. Sex differences in Aggressive Behavior in Children: Parents and Teacher's Reports. The Bangladesh Journal of Psychology, 1996, 16, 81-90.

Begum, R. Behavior Problem among Mentally Retarded Children. Birth order and the severity of Retardation. Bangladesh Psychological Studies, 1998, 8, 21-28.

Benjamin, B. L., D. Hanmer., L. Pawla., Crumrine, and R. L. Forehead. Birth order and sex interaction in child behavior problems. Developmental Psychology 2 1980, 16, 615-628.

Coie, J. D., K. A. Dodge, and R. Coppotelli. Dimensions and types of social status; a cross age perspective. Developmental Psychology, 1982, 18, 570-577.

Coie, J. D. and K. A. Dodge. Aggression and antisocial behavior. In W.V. Damon, ed. Handbook of child development, Vol. 3. Social, emotional, and personality development ( $5^{\text {th }}$ ed.). New York, J. Wiley, 1997, 786.

Coie, J. D., K. A. Dodge, and J. B. Kupersmidt. Peer group behavior and social status. In S.R. Asher and J.D. Coie, eds. Peer Rejection in Childhood. Cambridge, England: Cambridge University Press, 1990, 17-59.

Dollard, J., L.W. Doob., N. E. Miller., O. H. Mowrer, and R. R. Sears. Frustration and aggression. New Haven: Yale University Press, 1939.

Edwards, A. L. Manual Revised of Edwards personal preference schedule. The Psychological Corporation, New York, 1959.

Eisenman, R. Birth order, development, and personality. Acta Paedopsychiatrica International Journal of Child and Adolescent Psychiatry, 1992, 55, 25-27.

Elliot, D.S. Serious violent offenders: onset, developmental course, and termination. The American society of criminology 1993 presidential address. Criminology, 1994b, 32, 1-21. 
Eron, L. D. Understanding aggression. Presidential address, $9^{\text {th }}$ World Meeting of ISRA. Banff, 1990, June 12.

Eva. Personal values and aggression. Unpublished $\mathrm{PhD}$ thesis, University of Rajshahi, Rajshahi, 2003.

Gates, L., Limberger, M. R., Crockett, J., and Hubbard, J. Birth order and its relationship to depression, anxiety and self-concept test scores in children. Journal of Genetic Psychology, 1988, 149 (1), 29-34.

Hann, D.A. and N. Borek. Taking Stock of Risk Factors for Child/Youth Externalizing Behavior Problems. Bethesda, Maryland: National Institute of Mental Health, 2002, 2.

Hurlock, E. B. Child Development (6 ${ }^{\text {th }}$ edition). New York: McGraw-Hill, 1968.

Islam, S. and P. Huque. Behavior problem among the institutionalized children. Dhaka University Journal of Psychology, 1996, 20, 26-33.

Kushnir, T. A review of the evidence for birth order differences in anxiety and affiliation in stressful situations. Social Behaviour and Personality, 1978, 6, 179-186.

Leober, R., and D. F. Hay. Key issues in the development of aggression and violence from childhood to early adulthood. Annual Review of Psychology, 1997, 48, 371-410.

Maccoby, E. E. and C. M. Jacklin. The psychology of sex differences. Standard, CA: Stanford university press, 1974.

Owensn, L., A. Daly, and S, Phillip. Sex and Age Differences in Victimisation and Conflict Resolution Among Adolescents in a South Australian School. Aggressive Behavior, 2005, 31, 1-12.

Patrick, C. J., M. M Bradley, and P. J. Lang. Emotion in the criminal psychopath: Startle reflex modulation. Journal of Abnormal Psychology, 1993, 102, 83-92.

Pepler, D. J. and R. G. Slaby. For review of gender differences in aggressive behavior, see pages 44-50 in Theoretical and developmental perspectives on youth and violence. In L.D. Eron, J.H. Gentry, and P. Schlegel, eds. Reason to Hope: A Psychosocial Perspective on Youth and Violence, 1994.

Roberts, J., and J. T. Bird. Behavioral patterns of children in school: United Stats. Rockville, Md: U.S. Department of Health, Education, and Welfare, 1972. 
Schachter, S. Ordinal position, anxiety, and affiliation-1. In R. R. Sears, L. Festinger, and D. H. Lawrence and Schachter, S. Stanford Studies in Psychology: vol. 1. The Psychology of affiliation: Experimental studies of the sources of gregariousness, 1959, 42-61, Standford, CA: Stanford University Press.

Shanbhag, V. Factors influencing anxiety among adolescents. Indian journal of Behaviour, 1990, 14, 49-55.

Tapper, K., and J. B. Michael. Sex Differences in Levels of Physical, Verbal, and Indirect Aggression Amongst Primary School Children and Their Associations With Beliefs About Aggression. Aggressive Behavior, 2004, 30, 123-145.

Toldos M. P. Sex And Age Differences in Self-Estimated Physical, Verbal and Indirect Aggression in Spanish Adolescents. Aggressive Behavior, 2005, 31, 13-23.

Zervas, L. J. and M. F. Sherman. The relationship between perceived parental favoritism and self- esteem. Journal of Genetic Psychology, 1994, 155, 25-33. 